\title{
Scenario optimization asset and liability modelling for individual investors
}

\author{
Andrea Consiglio · Flavio Cocco • Stavros A. Zenios
}

Published online: 10 November 2006

(C) Springer Science + Business Media, LLC 2007

\begin{abstract}
We develop a scenario optimization model for asset and liability management of individual investors. The individual has a given level of initial wealth and a target goal to be reached within some time horizon. The individual must determine an asset allocation strategy so that the portfolio growth rate will be sufficient to reach the target. A scenario optimization model is formulated which maximizes the upside potential of the portfolio, with limits on the downside risk. Both upside and downside are measured vis-à-vis the goal. The stochastic behavior of asset returns is captured through bootstrap simulation, and the simulation is embedded in the model to determine the optimal portfolio. Post-optimality analysis using out-of-sample scenarios measures the probability of success of a given portfolio. It also allows us to estimate the required increase in the initial endowment so that the probability of success is improved.
\end{abstract}

Keywords Personal planning $\cdot$ Scenario optimization $\cdot$ Portfolio allocation

\section{Introduction}

The asset and liability modelling needs of individual investors deserve probably more attention than they have been getting thus far in the literature. Asset and liability modelling has focused almost exclusively on large institutions (Ziemba and Mulvey, 1998). This is not to

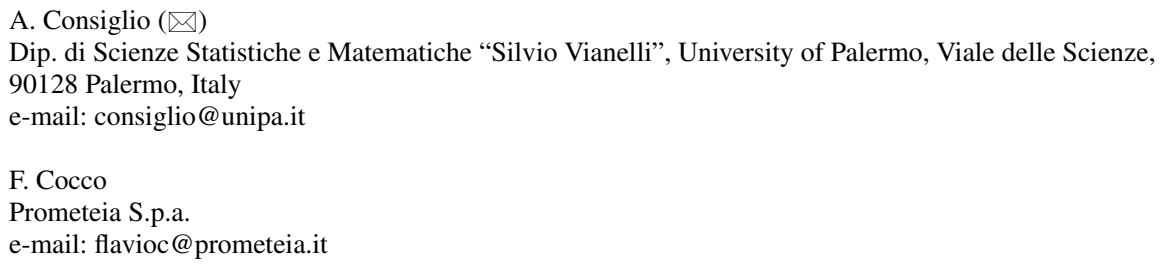


say that the individual has been ignored. On the contrary, literature on household portfolios is both vast and fast-growing (Guiso et al., 2001). In their state-of-the-art survey Guiso et al. describe the road ahead on research in this field as focusing on theory to explain contrasts between current theories and observed data on household portfolios, and empirical research to identify regularities in household portfolio behavior. The role of financial innovation and education in either preserving the observed trends, or reversing them, is identified by the authors as of potential interest to the financial industry marketing financial products to targeted groups. But the literature falls short of developing models for operationalizing the decision making process of the individual investors. Decision support tools that allow an individual to model his or her objectives to achieve pre-specified targets-assuming some optimality criterion-are scant. This is in contradiction to the developments in modeling the decision process of institutional investors or their agents, where the literature is extensive (e.g., Cario et al., 1998; Mulvey and Thorlacius, 1998).

Is this state of affairs surprising, given the "most important solid finding" by Guiso et al. that "most households do not diversify but specialize in the safest and most liquid asset"? Why have not financial innovation and education provided the tools and incentives for households to diversify? We argue that the current state of affairs is not surprising, but that it is changing. Our paper contributes towards this change.

Markowitz (1991) addressed these issues in a paper published in the inaugural issue of Financial Services Review. He pointed out that realistic game-of-life simulations would comprise of simulations of the family planning process - a complex and ill-structured processwith suitable models to optimize asset allocation for various approximations of the family planning process. His words are nowadays coming to fruition, with the World Wide Web giving to individual investors access to advisors carrying out their game-of-life simulations. Systems like FinancialEngines.com of Sharpe and Associates, and the HOME Account Advisor of Berger and Mulvey (1998) are the first manifestations of the attention paid to the asset and liability modelling needs of the individual investor. This support is coming at the time when individuals are becoming increasingly more sophisticated in their asset management needs, become aware of economic indicators in managing their wealth, and are transferring larger shares of their wealth from Banks to insurance companies and mutual funds or other asset managers (Harker and Zenios, 2000).

In addition to the technological advances outlined above, another sector contributed significantly to the transition towards decision support systems. Namely, the rapid growth of the literature on normative models that represent the intertemporal portfolio choice of individuals in a stochastic economic environment (Campbell and Viceira, 2002). This literature provides an insight to the equilibrium behaviour of an individual in various interesting environments, such as time-varying second moment of the markets, jump processes representing market crashes or bubbles and the like (e.g., Basak, 2002; Basak and Shapiro, 2001; Liu et al., 2003).

Armed with the insights from the continuous time models, and having at our disposal the required tools, the literature can now follow Markowitz' admonitions and develop models that incorporates more realistic requirements, such as, a large number of asset classes, operational constraints and intuitive objective functions.

In this paper we develop a scenario-based asset and liability modelling system for individual investors. This system has provided the engine for a web-based system that is currently supporting the clients of four banks in Italy (Consiglio, Cocco, and Zenios, 2004). In Section 2 we summarize the guidelines which we followed in outlining the model. In Section 3 we develop the mathematical model, and in Section 4 we discuss empirical results obtained with the solution of the model. An interesting feature of the model is that it replicates the behavior of individuals that gives rise to the equity premium puzzle (Mehra and Prescott, 1985). In 
particular we demonstrate that individuals adopting this model behave in ways hypothesized by Benartzi and Thaler (1995) in offering an explanation for the puzzle. Section 5 concludes the paper.

\section{Characteristics of a personal asset allocation model}

In this section we describe the characteristics that a personal asset allocation model should meet. We summarized them in the following points :

Simple language. We think it is very important to present to the investors a set of simple and intuitive questions from which to determine their investment framework. For example: What is your investment horizon? What is your final goal? How much is your initial endowment? In this way the users will interact with the model using their own language. For example, in a web environment there is no medium, as the bank officer, who can translate the customer's needs into the specific procedural language that a model could require.

Risk aversion. It is a common practice for banks to classify their customers according to their risk aversion. Usually, financial advisors determine investor's risk aversion through some questionnaires or computerized expert systems. This classification contains 4-5 risk profiles: from conservative to aggressive. We incorporate this information in our model so that the output portfolio is tailored to the investor's attitude towards risk.

Target first. We underline that the investors we are addressing in our analysis are retail ones. Their goals are tangible needs: building a house, sending the children to college, integrating pension income. For this reason one of the requirements of our model is to choose the asset allocation such that getting to the final target is the primary concern. Any surplus obtained must be saved in order to back any eventual deficit.

Success rate. Sometimes investors are not aware of how ambitious their project is. We associate to the investor' asset allocation the success rate of their project so that the initial endowment is commensurate to the final goal. We also suggest them how to improve the success rate by increasing the initial available capital. This can also be considered as a measure of the amount of savings needed by the investors during the project horizon to match their final target.

Risk measure. We are assuming that our investors are very sensitive to shortfall with respect to the final goal. For this reason, in the decision process more weight will be put on the deviations from the target. The risk measure will take into account of the shortfalls accumulated during the planning period.

The temporal dimension plays an important role in our model. The longer the horizon, the lower is the growth level needed to reach the target and, as we will show in Section 4.1, the greater is the probability of success. Furthermore, by coupling multiperiod scenarios with the implicit rebalancing strategy (target first!), which obliges the investor to match his target growth at the end of each period, the model is able to select portfolios which takes into account of the deviations occurring before the end of the investment horizon. Of course, we do not mean that the portfolio selected today must be kept for the whole planning horizon. The model proposed can be thought as a combination of a what-if analysis, carried over a set of scenarios, and an optimization tool whose objective is to identify that portfolio which mostly penalizes shortfalls below the target. In such a way, if the scenarios provided are sound, the real rebalance will be minimal. 
We believe this issue is also relevant for institutional investors. Using this model, portfolio managers will be able to make their strategic asset allocation by explicitly embedding the mismatch between the reporting and investment horizon. For example, life insurers dealing with minimum guarantee policies are obliged to participate the return of the linked portfolio at the end of each year, and any shortfall below the minimum guarantee must be backed by equity infusion. By integrating the asset-liability management (long term) with the annual reporting (short term), it will be possible to improve the final performance (see for details, Consiglio et al., 2001, 2003).

\section{The mathematics of the model}

We give here the model. Denote by $T$ the final period of the investor's horizon and by $t=$ $0,1,2, \ldots, T$, discrete points in time from today $(t=0)$ until $T$. Given an initial endowment $A_{0}$ and final target liability $L_{T}$, we denote by $A_{T}$ the terminal assets that will fund the liability $L_{T}$. The target rate of return that will yield adequate $A_{T}$ is given by

$$
g=\left(\frac{L_{T}}{A_{0}}\right)^{(1 / T)}-1 .
$$

The growth rate $g$ is the target rate of return on the initial endowment.

The development of the model is affected by two basic assumptions.

First, the nature of the liability is not explicitly postulated. It can be thought as a lump sum of money needed to afford a given outflow at the end of the planning period. The only factor which affects the liability is the price rises.

Second, as outlined in the previous section, our investors are retail ones and consider their target a cogent priority. They behave as purchasers of a single premium insurance policy to cover their future liability. For these reasons, they are not willing to consume part of the accumulated resources for other purposes and future incomes are not taken into consideration. This specific setup leads to a model where no optimal decisions are taken on inflows and outflows.

Each investor makes her decision by choosing at time $t=0$ a vector $\mathbf{x}=\left[\begin{array}{llll}x_{1} & x_{2} & \ldots & x_{N}\end{array}\right]^{T}$ whose $i$-th component denotes the fraction of initial endowment, $A_{0}$, invested in the $i$-th asset. The vector $\mathbf{x}$ must satisfy a set of constraints identified by the set $\mathbf{X} \subseteq \mathbb{R}^{+N}$.

Following the empirical findings of Kahneman and Tversky (1979), we model the behaviour of the investors in a way that they monitors the fluctuations in the value of their portfolio from period to period and not only at the end of the planned horizon.

For this purpose, we assume that the investors cover any deficit (downside) by cash infusion, i.e., increased savings on the part of the investors, and any surplus (upside) is set aside from the portfolio to back any future possible downside deviations from the target return.

Let $\tilde{u}_{t}$ and $\tilde{d}_{t}$ be two random variables which define the upsides and downsides in each time period $t=1,2, \ldots, T$. Given a capitalization factor $M_{t}{ }^{1}$, the random variable $\tilde{D}_{T}$ which accounts for the final deficit is given by

$$
\tilde{D}_{T}=\sum_{t=1}^{T} M_{t} \tilde{d}_{t} .
$$

\footnotetext{
${ }^{1}$ In general, $M_{t}$ is defined as $e^{\int_{t}^{T}} r(s) d s$, where $r(s)$ is the stochastic process of the spot interest rate. 且Springer
} 
The upsides collected during the planning horizon are added up to define the random variable of the final surplus

$$
\tilde{U}_{T}=\sum_{t=1}^{T} M_{t} \tilde{u}_{t}
$$

The investors will determine their portfolio by solving the following multiobjective programming model

$$
\begin{array}{ll}
\underset{\mathbf{x}}{\operatorname{Maximize}} & E\left[\tilde{U}_{T}\right]-\lambda E\left[\tilde{D}_{T}\right] \\
\text { s.t. } & \mathbf{x} \in \mathbf{X},
\end{array}
$$

where $\lambda>0$ is the risk aversion parameter.

An alternative equivalent formulation casts one of the two objective terms as a constraint

$$
\begin{array}{ll}
\underset{\mathbf{x}}{\operatorname{Maximize}} & E\left[\tilde{U}_{T}\right] \\
\text { s.t. } & \\
& E\left[\tilde{D}_{T}\right] \leq \omega \\
& \mathbf{x} \in \mathbf{X}
\end{array}
$$

The two models described above are equivalent in the sense that they produce the same efficient frontier; see Palmquist et al. $(2001,2002)$ for a proof of the statement in more general settings, and Dembo and Mausser (2000) for models with piece-wise linear equations.

A similar model is developed by Rudolf and Ziemba (2004). Their model is based on the dynamics of asset, liability, and a state variable. The surplus is defined as the difference between the asset and the liability variable at each time. Unlike the model presented here, in Rudolf and Ziemba's model the shortfall below the liability is given the same weight as the surplus. Moreover, they assume that the three processes follow a geometric Brownian motion, while our model makes no assumption about the dynamics of the variable involved.

It is easy now to see the relation of our model to Kahneman and Tversky's utility function, which is usually defined as follows

$$
\mathcal{U}(W)=\left\{\begin{array}{lc}
W^{\gamma}, & W \geq 0 \\
-\lambda(-W)^{\gamma}, & W<0 .
\end{array}\right.
$$

Empirical estimates usually find that $\gamma \gg 1$ producing a mild concavity over gains and convexity over losses. As stated in Barberis et al. (2001), this curvature is important when choosing between prospects that involve only gains or losses. When both losses and gains are involved the kink at $W=0$ is far more important than the curvature. For this reason and in order to simplify our formulation, we set $\gamma=1$. This special case of Kahneman and Tversky's utility function is precisely our Eq. (4).

It is also worth pointing out that the expected value of the losses plays the role of a risk measure, while the expected value of the surplus plays the role of a reward function. As it will be shown in the next section, by representing the probability distributions of the asset returns through a set of scenarios, the reward and the risk function formulated here turn out 
to be linear. See Dembo and Rosen (1999) for useful insights about bilinear utility functions for portfolio management.

Following Uryasev and Rockafellar (2000), we could reformulate the model identified by (6)-(8) as a CVaR constrained one. By letting $\xi$ to be the VaR of the portfolio and $\alpha$ the confidence level, the constraint (7) transforms into

$$
\xi+(1-\alpha)^{-1} E\left[\tilde{D}_{T}^{+}\right] \leq \omega
$$

where $\tilde{D}_{T}^{+}$is defined as

$$
\tilde{D}_{T}^{+}=\sum_{t=1}^{T} M_{t}\left(\tilde{d}_{t}-\xi\right)^{+}
$$

and $(h)^{+}$is the positive part of $h$.

\subsection{Model formulation}

In the financial markets uncertainty is captured in the form of a discrete set of scenarios denoted by $\Omega=\{1,2, \ldots, N\}$. The objective probability associated with each scenario $l \in \Omega$ is denoted by $p^{l}$. The investor chooses a portfolio from the universe of available assets $\mathcal{U}$, the returns of such instruments, during the period $t$ to $t+1$, are denoted by $r_{t i}^{l}$, for each $i \in \mathcal{U}$ and $l \in \Omega$.

To account for price appreciation, we adjust the target rate $g$ by scenarios of inflation rates, $I_{t}^{l}$, that apply from $t$ to $t+1$. The real target rate is given by

$$
g_{t}^{l}=g+I_{t}^{l}
$$

Note that, a more precise formulation of the real target rate should be

$$
g_{t}^{l}=(1+g)\left(1+I_{t}^{l}\right)-1=g+I_{t}^{l}+g I_{t}^{l} .
$$

However, given that $g I_{t}^{l} \approx 0$, we can approximate the real rate as in Eq. (12).

The portfolio value at each point in time is given by

$$
R_{P t}^{l}=\sum_{i=1}^{n} x_{i} r_{i t}^{l}, \quad \text { for } t=1,2, \ldots, T, \quad \text { and for all } l \in \Omega
$$

In our model the liability is the target which must be matched in each period by our asset portfolio in order to ensure that at the end of the planning period the final goal is fulfilled. The liability must grow at the rate given by $g_{t}^{l}$

$$
L_{t}^{l}=L_{t-1}^{l}\left(1+g_{t}^{l}\right) \quad \text { for } t=1,2, \ldots, T, \quad \text { and for all } l \in \Omega
$$

where $L_{0}=1$.

In order to match assets and liabilities in each period, we must infuse money every time a downside occurs. For the same reason, we reduce the current level of the portfolio value $\underline{\text { Springer }}$ 
when an upside is experienced, so that

$$
A_{t}^{l}=L_{t}^{l}, \quad \text { for } t=1,2, \ldots, T, \quad \text { and for all } l \in \Omega .
$$

The rule defined by Eq. (16), under all scenarios, acts as an implicit rebalancing rule, thus embedding intra-horizon deviations from the target liability in the actual portfolio selection. The request for Eq. (16) to hold is due to the incumbent concern of our retail investors whose cogent objective is to reach the desired target.

Given that equality (16) holds, the amount of capital to cover the deficit is given by

$$
d_{t}^{l}=\max \left[-\left(R_{P t}^{l}-g_{t}^{l}\right), 0\right] L_{t-1}^{l}, \quad \text { for } t=1,2, \ldots, T, \quad \text { and for all } l \in \Omega .
$$

Note that, $d_{t}^{l}$ depends only on the current mismatch between the portfolio rate of return and the target rate times the liability level at the previous period. The same logic applies to the surplus definition

$$
u_{t}^{l}=\max \left[\left(R_{P t}^{l}-g_{t}^{l}\right), 0\right] L_{t-1}^{l}, \quad \text { for } t=1,2, \ldots, T, \quad \text { and for all } l \in \Omega .
$$

We point out that the random variables $u_{t}^{l}$ and $d_{t}^{l}$ are piece-wise function of the returns of the portfolio. As a consequence, any linear combination of such variables will be a piece-wise linear function which is convex and concave at the same time.

The dynamics of the total deficit and total surplus are defined, respectively, as

$$
\begin{aligned}
& D_{t}^{l}=D_{t-1}^{l}\left(1+r_{f(t-1)}^{l}\right)+d_{t}^{l}, \quad \text { for } t=1,2, \ldots, T, \quad \text { and for all } l \in \Omega, \\
& U_{t}^{l}=U_{t-1}^{l}\left(1+r_{f(t-1)}^{l}\right)+u_{t}^{l}, \quad \text { for } t=1,2, \ldots, T, \quad \text { and for all } l \in \Omega,
\end{aligned}
$$

where, $r_{f t}^{l}$ is the short rate at $t$ under scenario $l$, and with the initial conditions that $D_{0}^{l}=$ $U_{0}^{l}=0$ for all $l \in \Omega$.

In view of (16), the dynamics of the assets are given by

$$
A_{t}^{l}=A_{t-1}^{l}\left(1+R_{P t}^{l}\right)-u_{t}^{l}+d_{t}^{l}, \quad \text { for } \quad t=1,2, \ldots, T, \quad \text { and for all } l \in \Omega .
$$

The max operator in (17) and (18) introduces a discontinuity in the model. To circumvent this problem, we introduce gap variables $y_{+t}^{l}$ and $y_{-t}^{l}$ to measure the portfolio excess return over the target rate and the shortfall below the target rate, respectively. Therefore, we have

$$
\begin{aligned}
& R_{P t}^{l}-g_{t}^{l}=y_{+t}^{l}-y_{-t}^{l}, \quad \text { for } t=1,2, \ldots, T, \quad \text { and for all } l \in \Omega, \\
& y_{+t}^{l} \geq 0, y_{-t}^{l} \geq 0, \quad \text { for } \quad t=1,2, \ldots, T, \quad \text { and for all } l \in \Omega .
\end{aligned}
$$

Only one of these variables can be nonzero for a given time and a given scenario. The dynamics for the deficit and surplus are now written as follows

$$
\begin{array}{ll}
d_{t}^{l}=y_{-t}^{l} L_{t-1}^{l}, & \text { for } \quad t=1,2, \ldots, T, \quad \text { and for all } l \in \Omega, \\
u_{t}^{l}=y_{+t}^{l} L_{t-1}^{l}, & \text { for } \quad t=1,2, \ldots, T, \quad \text { and for all } l \in \Omega .
\end{array}
$$

The optimal portfolio is chosen to maximize the expected value of the final surplus, $\sum_{l \in \Omega} p^{l} U_{T}^{l}$, subject to targets on expected value of the final deficit, $\sum_{l \in \Omega} p^{l} D_{T}^{l}$. A parameter 
$\omega$ specifies the bound on the downside risk; the lower this parameter, the less risk our investor is willing to assume to meet the targets.

Note that, all the constraints are linear except the expression for $A_{t}^{l}$ that, however, does not enter in the optimization model. Before we formulate the linear programming model, we can simplify some of the equalities to reduce the size of the problem. In Appendix A, we analytically determine the expressions for $U_{T}^{l}$ and $D_{T}^{l}$, and substitute them in the objective function to get a linear program. The resulting model becomes

$$
\begin{array}{ll}
\text { Maximize } & \sum_{l \in \Omega} p^{l} \sum_{t=1}^{T} y_{+t}^{l} \Phi^{l}(t, T) \\
\text { s.t. } & \sum_{i=1}^{m} x_{i}=1 \\
& \sum_{l \in p} p^{l} \sum_{t=1}^{T} y_{-t}^{l} \Phi^{l}(t, T) \leq \omega \\
& R_{P t}^{l}-g_{t}^{l}=y_{+t}^{l}-y_{-t}^{l}, \quad \text { for } t=1,2, \ldots, T, \\
& R_{P t}^{l}=\sum_{i=1}^{m} x_{i} r_{i t}^{l}, \quad \text { for } t=1,2, \ldots, T, \\
& \quad \text { and for all } l \in \Omega, \\
& y_{+t}^{l}, y_{-t}^{l} \geq 0, \quad \text { for } t=1,2, \ldots, T, \\
& x_{i} \geq 0, \quad \text { for } i=1,2, \ldots, N
\end{array}
$$

where,

$$
\Phi^{l}(t, T)=\prod_{\tau=0}^{t-1}\left(1+g_{\tau}^{l}\right) \prod_{\tau=t}^{T}\left(1+r_{f \tau}^{l}\right)
$$

with boundary conditions $g_{0}=0$ and $r_{f T}=0$, that is, the target rate of return is zero before the first time period and the risk free rate is zero at the end of the horizon.

The surplus and the deficit are accumulated at the risk free rate. We could have used a spread between borrowing and lending rates. However, this trivial technical modification is not essential for portfolio selection since the same efficient frontier will be obtained when varying the parameters $\omega$.

Equation (28) defines the risk function for the selection model above described. Note that, deficits occurring in the early periods are weighted more than those occurring later on. This guarantees that the model chooses portfolios which are more conservative with respect to those assets whose returns perform poorly in the early stages. In a recent paper, Kritzman and Rich (2002), arguing that investors are affected by losses throughout the investment period, introduce two new risk measures-within-horizon probability of loss and continuous VaR. Our contribution confirms their intuitions and provides a more general framework. First, as just remarked, we weight differently losses occurring in different time periods and use these 
weights to select our portfolio. Second, going beyond Kritzman and Rich, who develop their measures assuming a Gaussian distribution of the assets return, our model is implemented using scenarios that may be drawn from an arbitrary distribution.

A possible extension of the above model will include consumption and saving decision variables. Given a set of scenarios for the labor income, $I_{t}^{l}$, we denote by $C_{t}$ the amount of current wealth which is consumed at time $t$, and by $S_{t}$ the amount of income saved and invested in the asset account. The dynamics of the assets will turn into

$$
\begin{aligned}
A_{t}^{l}= & A_{t-1}^{l}\left(1+R_{P t}^{l}\right)-u_{t}^{l}+d_{t}^{l}+ \\
& -C_{t}+S_{t}, \quad \text { for } t=1,2, \ldots, T, \quad \text { and for all } l \in \Omega,
\end{aligned}
$$

where $C_{t} \geq 0$ and $0 \leq S_{t} \leq I_{t}^{l}$.

The objective function can be casted to maximize the utility of consumption over all periods, $\sum_{i=1}^{T} C_{t}$, and minimize the saving decisions, $\sum_{i=1}^{T} S_{t}$. Also note that, constraints on the level of the saving and consumption variables can be easily added.

\subsection{Analysis of the model}

Solving this model we obtain an optimal portfolio and estimate its upside potential and downside risk. Post-optimality analysis can be carried out to estimate quantities that are not readily available from the model but that are important in a game-of-life simulation. In particular, we can estimate the probability that a given asset allocation will meet the target. We can also estimate the amount of additional capital required to improve this probability to an acceptable level $100 \alpha \%$.

We first estimate the probability of success of a given allocation. We denote by $\Omega^{\prime}$ an out-of-sample set of scenarios of asset returns. We then calculate $A_{T}^{l}$ and $L_{T}^{l}$ for each $l \in \Omega^{\prime}$ and define by $\Delta_{T}^{l}=A_{T}^{l}-L_{T}^{l}$ the asset/liability mismatch at the end of the horizon. We determine the present value of $\Delta_{T}^{l}$ using a discount factor $v^{l}(0, T)$. This factor could be scenario dependent, we discuss later possible choices of the discount factor. The present value of the mismatch is then given by

$$
\Delta_{0}^{l}=\Delta_{T}^{l} v^{l}(0, T)
$$

The probability of success can be estimated from the empirical cumulative distribution function of the present value of the mismatch $\Delta_{0}^{l}$. Assuming for simplicity that all out-ofsample scenarios are equally likely, we write the cumulative distribution function as

$$
F(h)=\frac{1}{N^{\prime}} \sum_{l \in \Omega^{\prime}} \delta_{\left\{\Delta_{0}^{l} \leq h\right\}},
$$

where $\delta_{\{\cdot\}}$ is the indicator function taking the value 1 when the expression in its subscript is true, and 0 otherwise. The probability of success is then given by

$$
\mathrm{PoS}=1-F(0)
$$

We can also use $F(h)$ to determine the percentile, $\Delta_{0}^{*}$, at the confidence level $\alpha$, such that

$$
P\left(\Delta_{0}^{l} \leq \Delta_{0}^{*}\right)=\alpha,
$$


or, equivalently

$$
1-F\left(\Delta_{0}^{*}\right)=1-\alpha
$$

It follows that adding $\Delta_{0}^{*}$ to the initial endowment the distribution of the final mismatch shifts to the right. Thus, the probability of getting a final mismatch with present value less than zero will be less than $100(1-\alpha) \%$.

We denote by $\Delta_{0}^{*}$ the amount of money that added to the initial endowment makes at least equal to $100(1-\alpha) \%$.

The second point of the post-optimality analysis concerns the discount factor $v(0, T)$. How should we discount the final mismatch $\Delta_{T}^{l}$ ? The answer depends on the instrument in which we will invest the amount $\Delta_{0}^{*}$ to improve the probability of success. If we invest $\Delta_{0}^{*}$ in the optimal portfolio, we have

$$
v^{l}(0, T)=\frac{1}{\prod_{\tau=1}^{T}\left(1+R_{P t}^{l}\right)} .
$$

If we choose a safer instrument such as a risk free deposit with forward rates $f_{t \tau}^{l}$ we have

$$
v^{l}(0, T)=\frac{1}{\prod_{t=0}^{T}\left(1+f_{t(t+1)}^{l}\right)} .
$$

By choosing the risky discount factor, we reduce the amount of money to be infused, but then the investor is more exposed to adverse moves of the market. In alternative, by choosing the risk free discount factor adverse scenarios will affect only the initial endowment. The supplementary funds are preserved to back future asset and liability mismatch.

\section{Model validation and testing}

The model was implemented in the algebraic modelling language GAMS of Brooke, Kendrick, and Meeraus (1992), and it provided the engine for a web-based decision support system for individuals, see Consiglio, Cocco, and Zenios (2004). We test here the model on a range of planning horizons, target returns, and risk tolerances. The set of asset classes are represented by benchmark indices as summarized in Table 1 .

In our validation we did not address the impact of the demand for real estates on the investors' portfolio composition. This issue is analyzed in Flavin and Yamashita (2002). They found that for reasonable level of the risk aversion parameter the amount invested in stock changes dramatically, going from a very low level (1\%) for the age segment $18-30$, to an high level (60\%) for the age segment 70 and over.

Scenarios are generated by bootstrapping a set of historical monthly records for the thirteen years period from Jan. 1988 to Feb. 2001 (see Appendix B for summary statistics of the historical series used). In order to take into account the different currencies, we considered the historical monthly records of the exchange rates akin asset classes and proceeded to sample them in conjunction with the returns of the selected benchmarks. Each scenario is a vector of returns of the assets obtained by sampling returns that were observed during this period. Dates from the available historical records are selected randomly, and for each date in the sample we read the returns of all assets classes realized during the previous month. 
Table 1 Benchmarks and corresponding asset classes

\begin{tabular}{ll}
\hline DataStream Code & Asset Class \\
\hline MSNAMR & Stocks North-America \\
MSPACF & Stocks Pacific \\
MSEMKG & Stocks Emerging Countries \\
MSEMUI & Stocks EMU \\
MSEXEM & Stocks Ex-EMU \\
JPMUSU & Bonds North-America \\
JPMJPU & Bonds Pacific \\
JAGALL & Bonds EMU \\
JPMUKU + SBSZEUE & Bonds Ex-EMU \\
JPMPTOT & Bonds Emerging Countries \\
JPEC3M & Cash \\
\hline
\end{tabular}

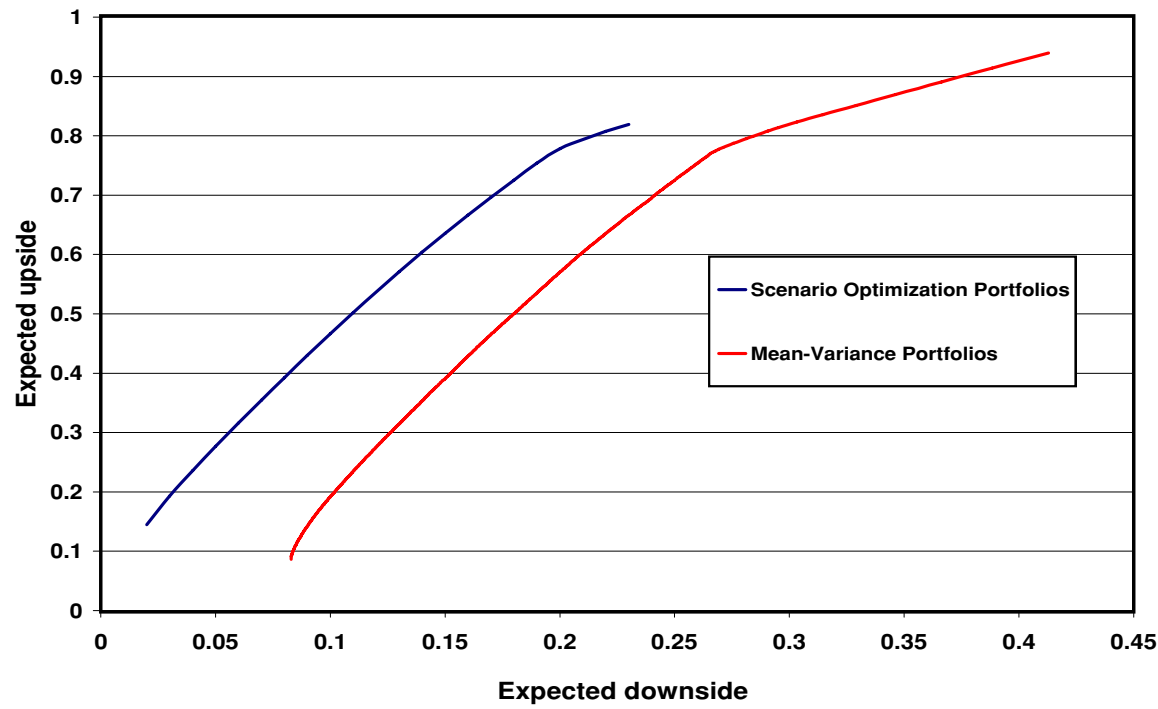

Fig. 1 Expected upside and expected downside of mean-variance efficient portfolios and of portfolios obtained with the scenario optimization model

These samples are scenarios of monthly returns. To generate scenarios of returns for a long horizon—say 10 years—we sample 120 monthly returns from different points in time. The compounded return of the sampled series is one scenario of the 10 -year return. The process is repeated to generate the desired number of scenarios for the 10 -year period. With this approach the correlations among asset classes are preserved, see for example Jorion (2001).

Numerical experiments are carried out for target returns between $4 \%$ to $15 \%$ with increments of $1 \%$, for time horizons ranging from 1 to 10 years with increments of 1 year. Limits on the downside risk $\omega$ are imposed in the range $[0,10]$, where $\omega=0$ corresponds to very high risk aversion, usually leading to an infeasible optimization model, and $\omega=10$ corresponds to high appetite for risk.

In our experiments we grouped the risk aversion of the investor in three classes labelled high, medium and low, corresponding to the values of $\omega$ in the range $0-3,4-7$, and $8-10$, respectively.

For each asset class we generated 1000 scenarios of returns during the target horizons $T$. The target horizon is then discretized in quarterly, semiannual or annual periods indicating 

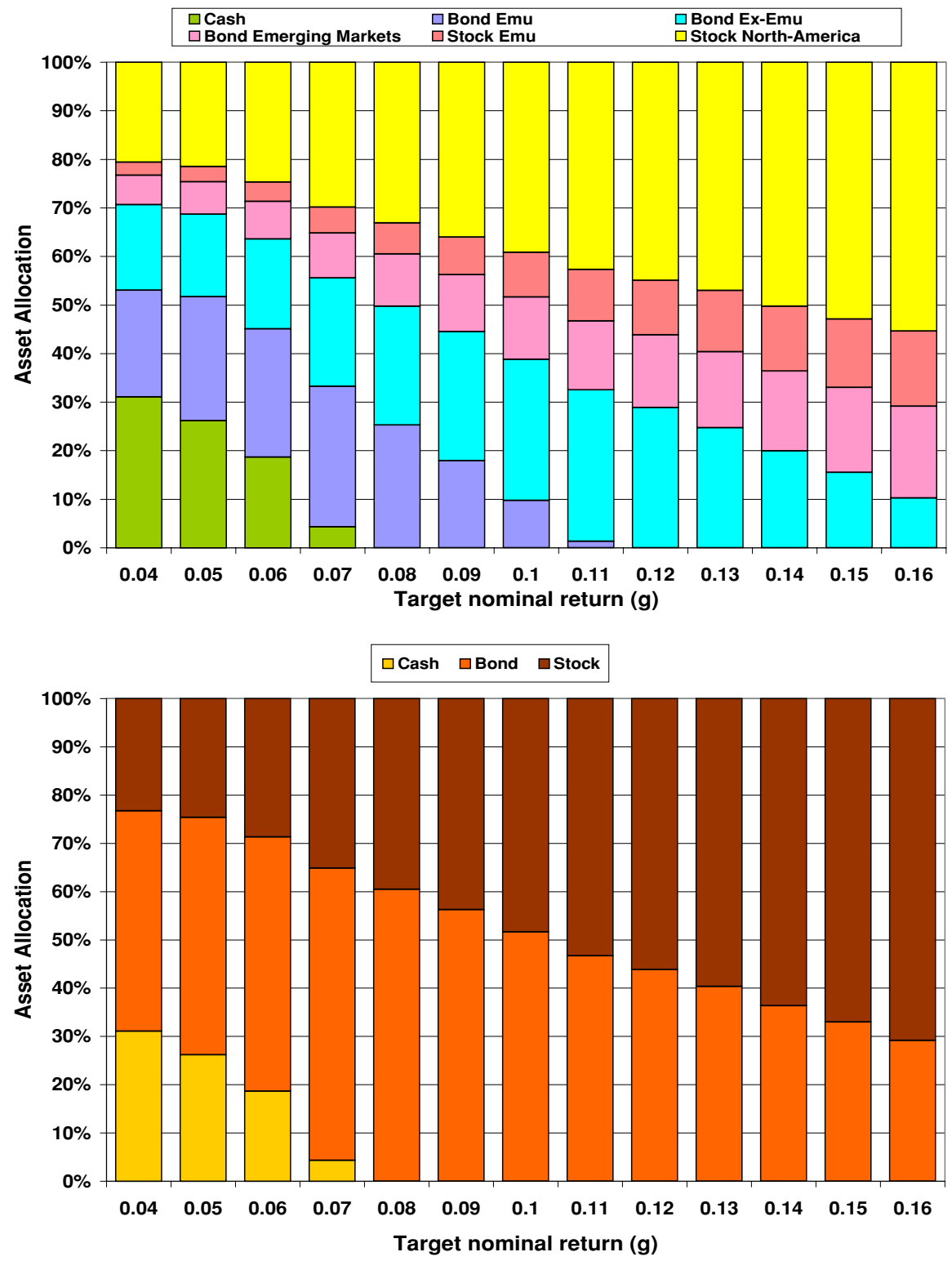

Fig. 2 Asset allocations for each class (up) and for broad class (down) for time horizon of 5 years and risk aversion high, with increasing target nominal returns

the trading dates $(t)$ when the model equations apply. To maintain tractability of the model the discretization depends on the length of the horizon, with finer discretization being possible only for short horizons.

As a first step we compared the scenario based model that integrates the asset allocation with the investor's target to the classical approach of asset allocation based on the meanvariance analysis. We built an efficient frontier using mean-variance optimization and then 包 Springer 

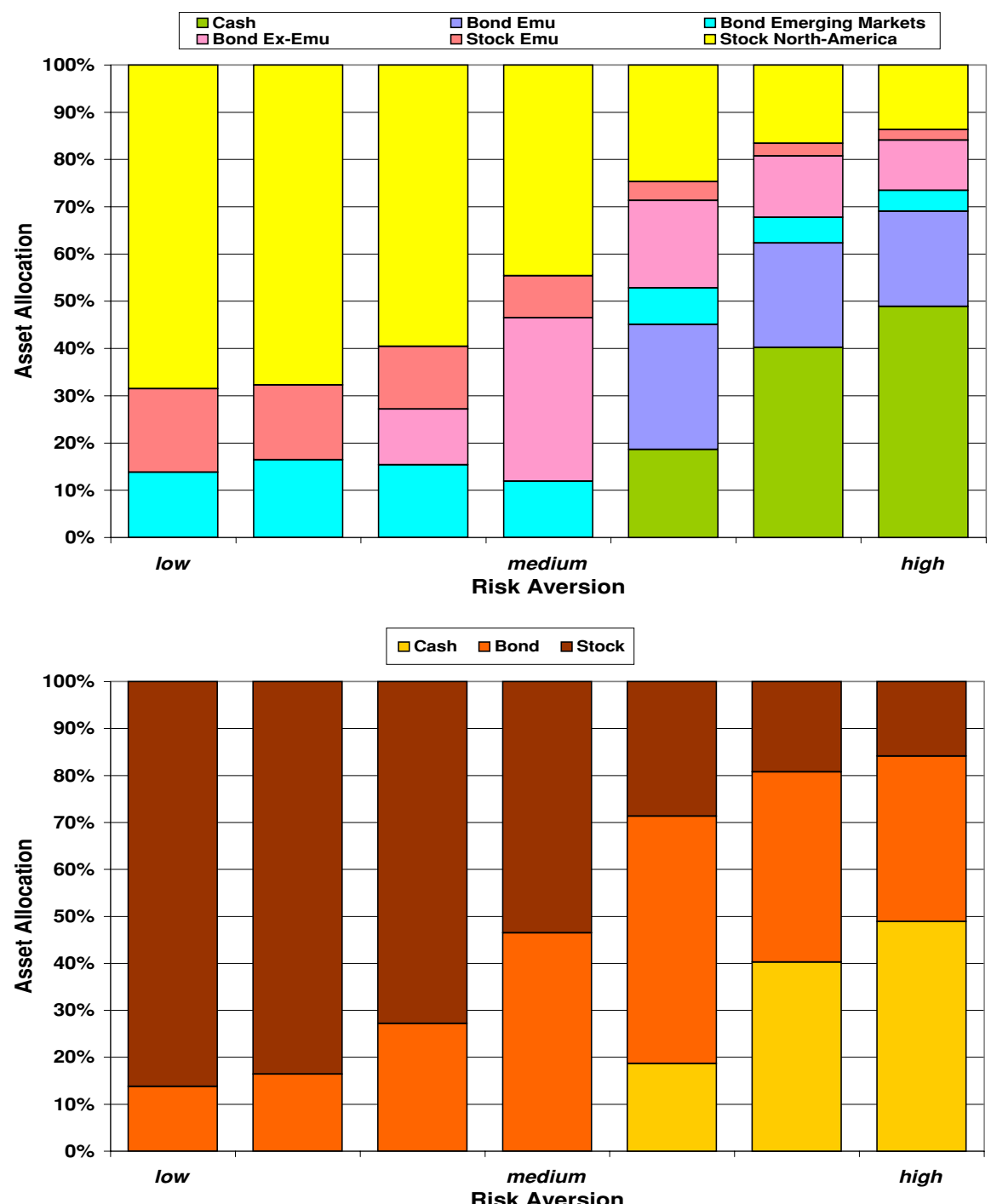

Fig. 3 Asset allocations for each class (up) and for broad class (down) for $T=5, g=6 \%$ and different levels of risk aversion

analyzed the expected upside and the expected downside of the efficient portfolios vis-à-vis a nominal target return of $6 \%$. The results are shown in Fig. 1, together with the frontier of expected upside versus expected downside obtained with the scenario optimization model. We observe that the portfolios obtained with the scenario optimization model dominate those obtained with the mean-variance analysis. Furthermore, the frontier is extended for lower downside risk than what is achieved with the mean-variance analysis. It is noteworthy that the difference between the two sets of portfolios is substantial. Further improvements are possible when short sales are allowed; the relevant efficient frontier is pushed significantly towards higher expected returns than those shown in the figure. 


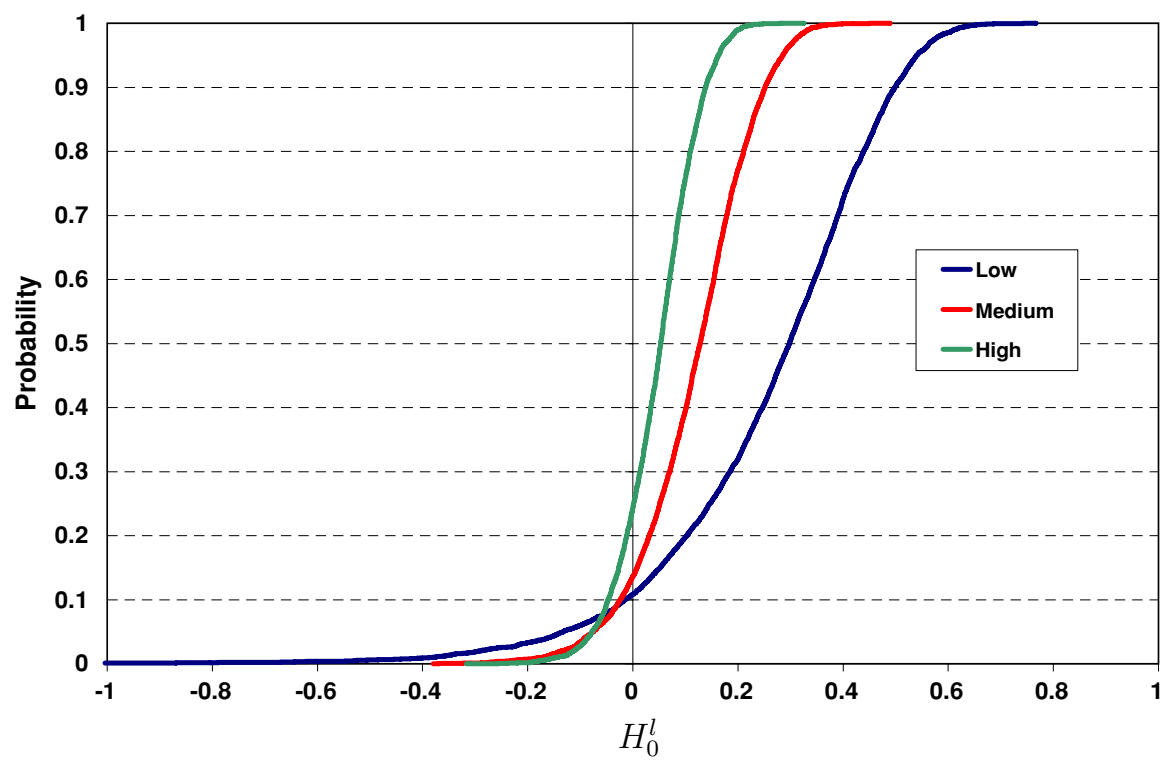

Fig. 4 Empirical cumulative distribution function for $T=5, g=6 \%$ and different levels of the risk aversion. The probability of success is given by one minus the intercept of the vertical axis at zero. The lower is the risk aversion, the higher is the probability of success. However, a lower risk aversion has a negative impact on the tail of the loss distribution. In fact, it increases the probability of negative extreme events, and therefore, the probability of not matching the final target

We then tested the composition of the portfolio for different target rates of return. The asset allocations for different levels of target return are shown in Fig. 2. We observe a transition to more risky portfolios as the target return increases. Even if investors do not change their risk aversion, their portfolio becomes riskier in order to achieve their goals. When investors keep their target return fixed and increase their risk aversion the portfolio composition will change, as expected, towards more conservative instruments. This is illustrated in Fig. 3.

While each one of these observations, on its own, is rather trivial, together they reveal an important dilemma for the individual investor. In particular, it is only with more appetite for risk that higher targets can be reached. The probability of success will deteriorate if investors keep the target return constant and increase their risk aversion; this is shown in Fig. 4. For high risk aversion the probability of success is about $75 \%$ and it increases to $90 \%$ for individuals ready to take more risks. However, note that the tail of the distribution is more pronounced towards the left for risk lovers, indicating higher losses in case of adverse scenarios. These results are confirmed in other studies, such as Milevsky et al. (1997).

We show in Fig. 5 the asset allocations as we vary the individual's time horizons. As expected, with the increase of the time horizon we observe a gradual shift towards more risky investments, the total exposure to cash and EMU bonds declines, and the difference is taken up by investments in the North American stock market indices, emerging market bonds and non-EMU bonds.

We also observe that the model replicates the investor's behavior that gives rise to the equity premium puzzle (Mehra and Prescott, 1985) and, in particular, it shows conditions under which investors prefer more secure investments even for reasonable levels of risk aversion. From the results of Fig. 6 we observe that as we decrease the discretization step, thus 

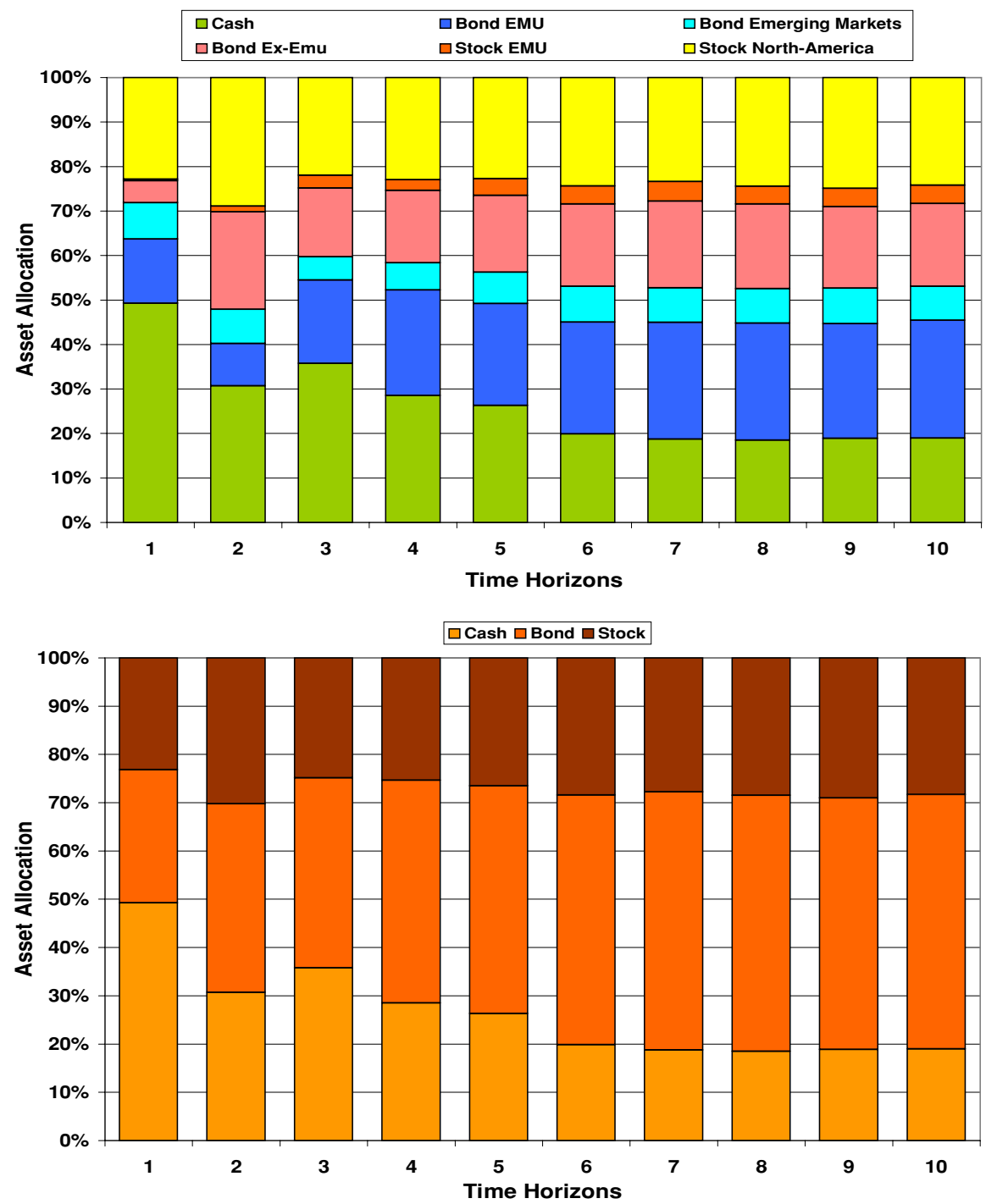

Fig. 5 Asset allocations for each class (up) and for broad class (down) for target return 6\%, different time horizons, and risk aversion high

increasing the frequency with which individuals examine the performance of their portfolios vis-à-vis their goals, the asset allocation shifts towards secure investments. The investors of our model exhibit myopic loss aversion, as characterized by Benartzi and Thaler (1995).

\subsection{Probability of success and how to improve it}

We now analyze the probability of success for different portfolios and show how this probability can be improved by increasing the initial endowment. We carried out our experiments by generating a set of 5000 out-of-sample scenarios; these are different from the 1000 scenarios used in the optimization model. For each scenario we computed the final mismatch 

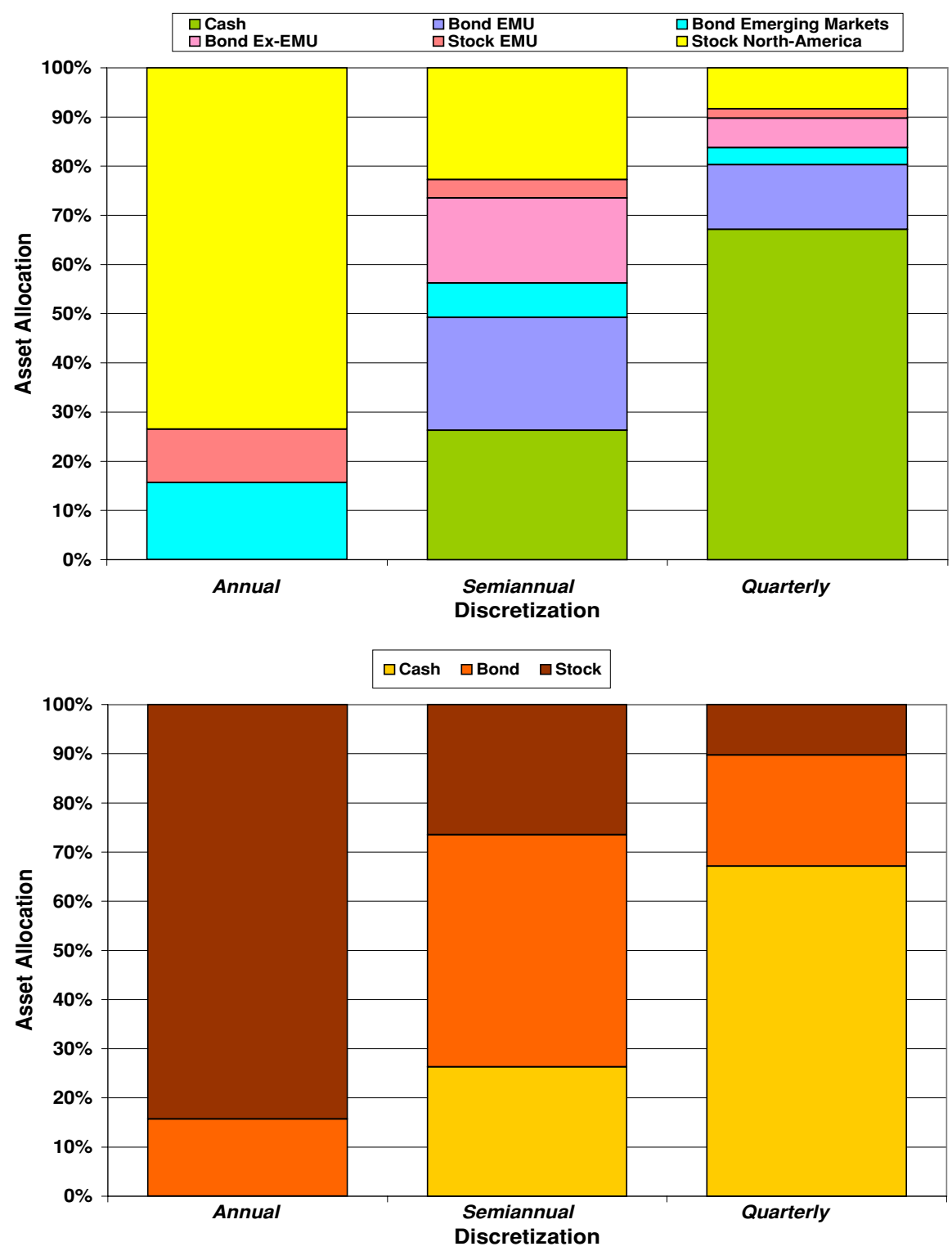

Fig. 6 Asset allocations for each class (up) and for broad class (down) for target return 6\%, time horizon five years, and risk aversion high as we decrease the discretization time step

$\Delta_{T}^{l}$, and then drawn the cumulative distribution function. The mismatch is discounted either at the rate of the risky portfolio or at the risk free rate.

Figure 7 illustrates the cumulative distributions, showing also the probability of success, for different target returns. The tails of these distributions are shown in Fig. 8, where we also show the amount of money (per unit of initial investment) that must be infused to the initial endowment to back future shortfalls. Two different amounts are calculated for each target return that will improve, respectively, the probability of success to $95 \%$ or $90 \%$. For Q Springer 


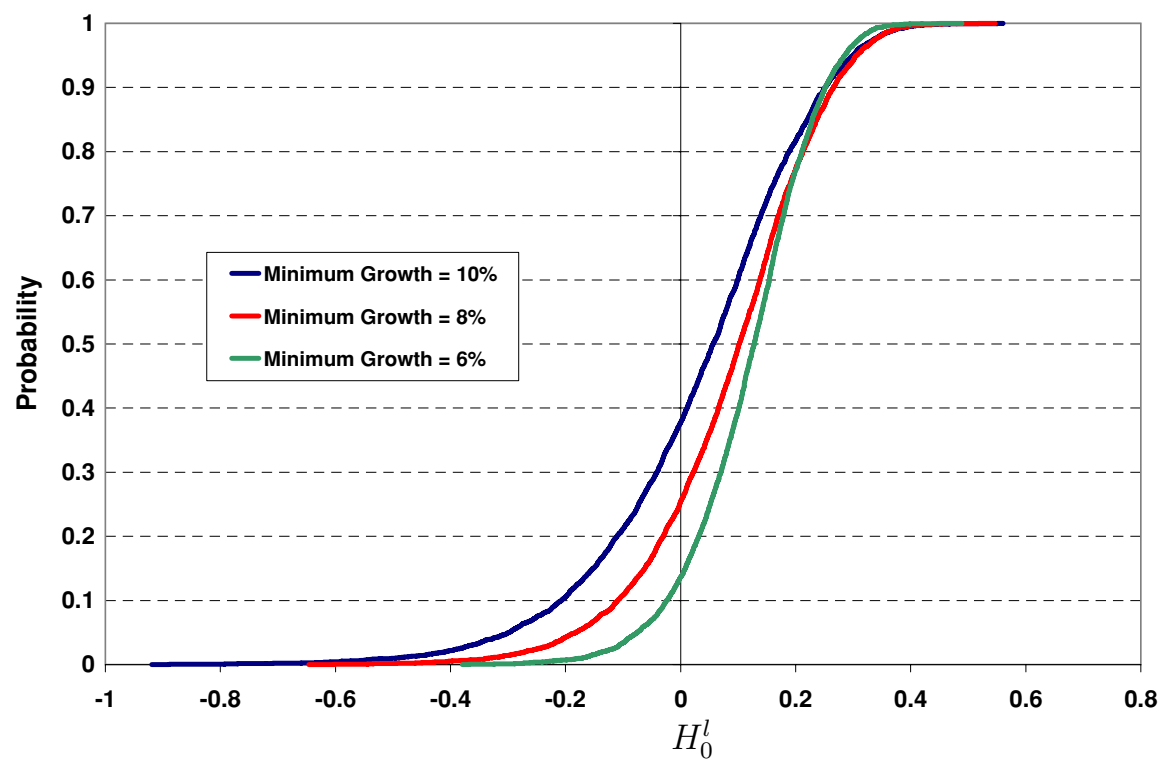

Fig. 7 Empirical cumulative distribution function for $T=5$, risk aversion medium, and different levels of the minimum growth rate $g$

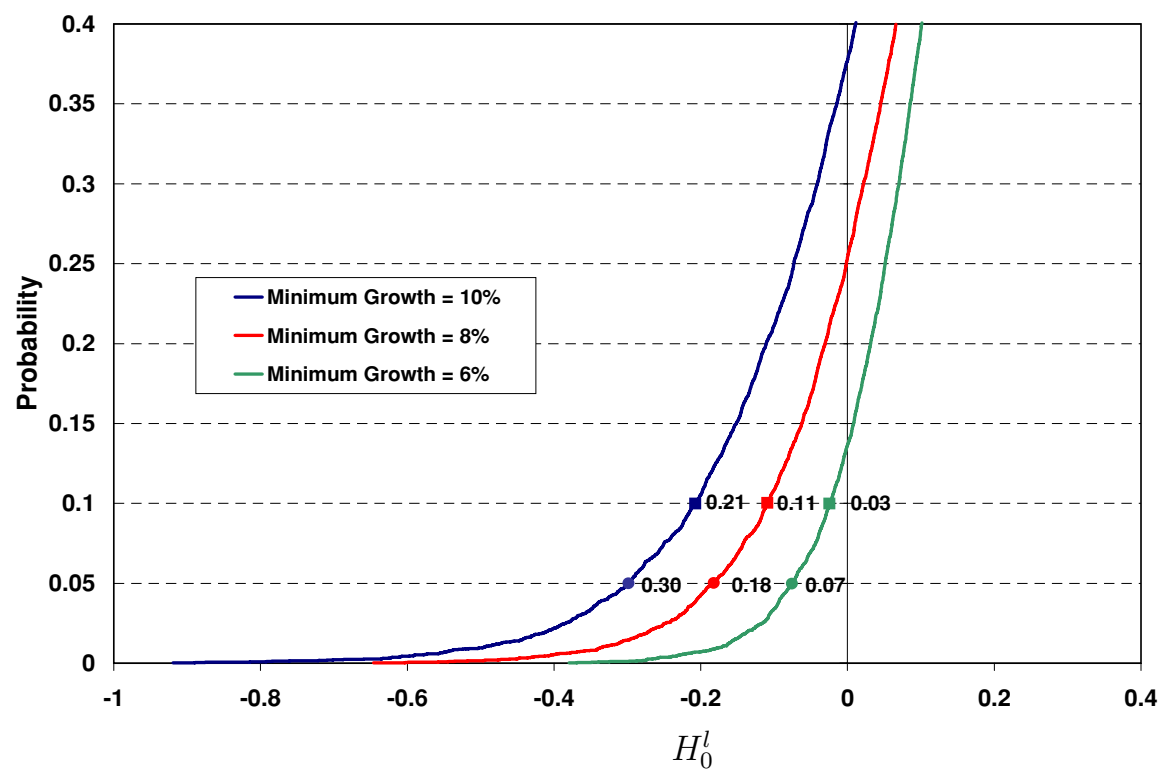

Fig. 8 Percentiles for $T=5$, high risk aversion and different levels of the target rate $g$. The labels report the amount of cash infusion, in \% of the initial endowment, needed to improve the success rate 


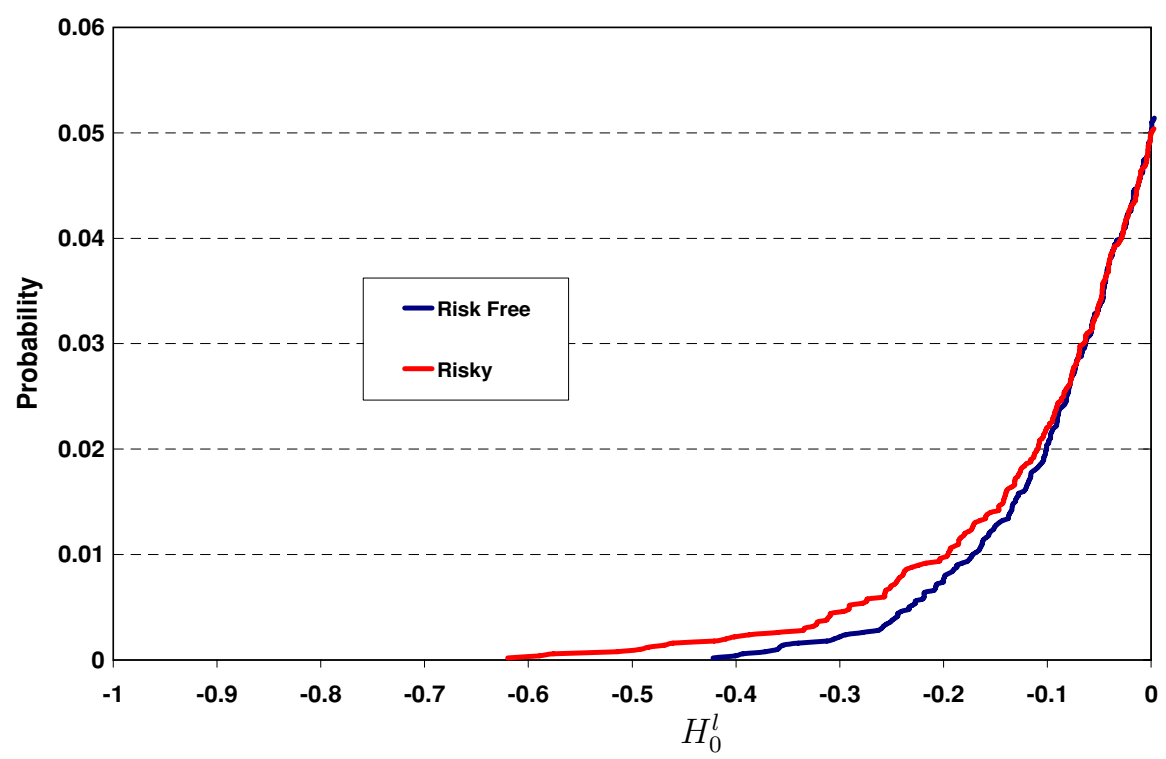

Fig. 9 Detail of the tails of the distribution of the asset/liability mismatch after the cash is added to the initial endowment and is invested either in the risky portfolio or in a risk free asset

example, to achieve a confidence level of $95 \%$ of reaching a $6 \%$ target rate for five years, we must add 0.07 euro for each euro of initial endowment. To have a $90 \%$ probability of success in reaching $10 \%$ annual growth rate for the same horizon we must infuse .21 euro per euro of the initial capital.

Finally, we show the effect of different discount factors on the cumulative distribution curves $F(h)$. By discounting the final asset/liability mismatch at the rate of the asset portfolio, we assume that the additional cash that will fund shortfalls is invested in the optimal portfolio. A safer strategy would be to invest the infused cash in a risk free deposit. Figure 9 shows the tails of the distribution after sufficient cash are added to the initial endowment to improve the success rate to $95 \%$. We observe, however, that the shortfall when not meeting the target is higher than when investing the additional cash in the risky portfolio.

\section{Conclusions}

We have developed and tested a normative model for assisting individual investors in making asset allocation decisions to meet some targets. The model improves upon the classical meanvariance analysis for asset allocation and it is consistent with prevailing positive theories about the investor behavior. As such it can contribute to the needs of individual investors for asset and liability management, an area for which apparently there is increasing demand on the part of consumers. Extensive empirical analysis provides some insights in the performance of the model.

An interesting extension of the model would be into a multi-stage multi-period setting to account for investor targets that change with time, and whereby investors may change their asset mix as new information arrives. Such an extension is feasible using the techniques of stochastic programming. This approach may also be warranted given the fact that individuals Q Springer 
do face multiple liabilities, and they do revise their portfolios as time goes by. On the other hand the conceptual demands imposed on the individual from a more integrative approach may be prohibitive.

\section{Appendix A: Solving the linear dynamic equations}

The linear discrete dynamic equation which describes the evolution of the deficit, cf. Equation (19), can be solved analytically to obtain the value of $D_{T}^{l}$ at the end of the planning horizon. To simplify the notation we drop the scenario superscript. It is easy to see that

$$
L_{t}=\prod_{\tau=1}^{t}\left(1+g_{\tau}\right)
$$

where $L_{0}=1$.

At time $t=0$, no deficit has occurred and $D_{0}=0$. At $t=1$ we have

$$
D_{1}=D_{0}\left(1+r_{f 0}\right)+y_{-1} L_{0}
$$

At $t=2$, we have $D_{2}=D_{1}\left(1+r_{f 1}\right)+y_{-2} L_{1}$ and substituting for $D_{1}$ from (43) we obtain

$$
D_{2}=y_{-1}\left(1+r_{f 1}\right)+y_{-2}\left(1+g_{1}\right) \text {. }
$$

Repeating for $t=3$ we obtain

$$
\begin{aligned}
D_{3}= & D_{2}\left(1+r_{f 2}\right)+y_{-3} L_{2} \\
= & y_{-1}\left(1+r_{f 1}\right)\left(1+r_{f 2}\right)+y_{-2}\left(1+g_{1}\right)\left(1+r_{f 2}\right) \\
& +y_{-3}\left(1+g_{1}\right)\left(1+g_{2}\right) .
\end{aligned}
$$

Repeating this process recursively for each $t$, we determine the expression for the final deficit

$$
D_{T}=\sum_{t=1}^{T} y_{-t} \prod_{\tau=1}^{t-1}\left(1+g_{\tau}\right) \prod_{\tau=t}^{T}\left(1+r_{f \tau}\right) .
$$

We also have the boundary conditions $g_{0}=0$ and $r_{f T}=0$, so that the target rate of return is zero before the first time period and the risk free rate is zero at the end of the horizon. To simplify the notation of the model, we define

$$
\Phi^{l}(t, T)=\prod_{\tau=0}^{t-1}\left(1+g_{\tau}^{l}\right) \prod_{\tau=t}^{T}\left(1+r_{f \tau}^{l}\right) .
$$

Applying the same argument to the dynamics of the surplus, we obtain

$$
U_{T}=\sum_{t=1}^{T} y_{+t} \prod_{\tau=1}^{t-1}\left(1+g_{\tau}\right) \prod_{\tau=t}^{T}\left(1+r_{f \tau}\right) .
$$


Table 2 Summary statistics for monthly returns of the asset classes over the entire sample period from February 1, 1998 to November 1, 2000

\begin{tabular}{lllll}
\hline DataStream Code & Mean & Standard Deviation & Excess Kurtosis & Skewness \\
\hline MSNAMR & 0.01343 & 0.03824 & 1.619 & -0.60 \\
MSPACF & 0.00030 & 0.05805 & 1.685 & -0.46 \\
MSEMKG & 0.00824 & 0.06978 & 3.197 & -0.98 \\
MSEMUI & 0.01393 & 0.04875 & 2.193 & -0.75 \\
MSEXEM & 0.01204 & 0.04183 & 1.365 & -0.28 \\
JPMUSU & 0.00647 & 0.01245 & 0.090 & -0.10 \\
JPMJPU & 0.00456 & 0.01404 & 0.858 & -0.11 \\
JAGALL & 0.00716 & 0.01118 & 0.217 & -0.38 \\
JPMUKU & 0.00826 & 0.01850 & 0.735 & -0.17 \\
SBSZEUE & 0.00450 & 0.01759 & 2.660 & 0.871 \\
JPMPTOT & 0.01209 & 0.05425 & 11.61 & -2.38 \\
JPEC3M & 0.00598 & 0.00486 & 2.270 & 0.266 \\
\hline
\end{tabular}

\section{Appendix B: Statistical analysis of the data}

In this appendix we show some summary statistics of the historical series used for the portfolios selection and we test the selected series to asses whether the elements of the sample are identically and independently distributed (IID).

A powerful test used for independence (and, under certain circumstances, for non-linear dependencies) was developed by Brock et al. (1996) and is based on the correlation integral. The BDS statistic tests the null hypothesis that the elements of a time series are independently and identically distributed (IID). For a time series which is IID, the distribution of the statistic:

$$
W_{m, T}(\epsilon)=\frac{\sqrt{T}\left[C_{m, T}(\epsilon)-C_{1, T}^{m}(\epsilon)\right]}{\sqrt{\sigma_{m, T}^{2}(\epsilon)}}
$$

is asymptotically $N(0,1)$, where, $C_{m}(\epsilon)$ is the correlation integral denoting the fraction of $m$-tuples in the series which are within a distance, $\epsilon$, of each other, and $\sigma_{m}^{2}(\epsilon)$ is an estimate of the standard deviation under the null hypothesis of IID. The null hypothesis is rejected if the test statistic is large in absolute value, (say greater than 1.96).

Usually, $\epsilon$ is defined in terms of the standard deviation of the sample $\sigma$. In our analysis, we computed the BDS statistic for $\epsilon=k \sigma$ with $k=0.5,1,1.5,2$, and embedded dimension $m=2,3$. The results are displayed in Table 3 . We note that, only for the asset class JPEC3M, which denotes the investment in cash, we can strongly reject the hypothesis of IID. All the other series show evidence in favour of the null hypothesis of serially IID.

\section{Appendix C: Sensitivity analysis}

We analyze in this section the sensitivity of the model to the sampling error. Further analysis should be carried out in order to assess how robust is the model with respect to the misspecification of the scenario generation procedure. In particular, the bootstrap method described in Section 4 suffers of some serious drawbacks when the returns of the series are not IID. However, it is important to underline that this misspecification mainly leads to inconsistent 
Table 3 BDS statistics and $p$-values (among parenthesis) for monthly returns of the asset classes over the entire sample period from February 1, 1998 to November 1, 2000. We test the hypothesis that series are IID.

\begin{tabular}{|c|c|c|c|c|c|c|c|c|}
\hline & \multicolumn{4}{|c|}{$m=2$} & \multicolumn{4}{|c|}{$m=3$} \\
\hline & $0.5 \sigma$ & $\sigma$ & $1.5 \sigma$ & $2 \sigma$ & $0.5 \sigma$ & $\sigma$ & $1.5 \sigma$ & $2 \sigma$ \\
\hline MSNAMR & $\begin{array}{l}0.66 \\
(0.50)\end{array}$ & $\begin{array}{l}0.77 \\
(0.44)\end{array}$ & $\begin{array}{l}0.36 \\
(0.72)\end{array}$ & $\begin{array}{r}-0.25 \\
(0.80)\end{array}$ & $\begin{array}{l}0.63 \\
(0.53)\end{array}$ & $\begin{array}{l}1.28 \\
(0.20)\end{array}$ & $\begin{array}{l}0.49 \\
(0.62)\end{array}$ & $\begin{array}{l}0.11 \\
(0.91)\end{array}$ \\
\hline MSPACF & $\begin{array}{l}0.79 \\
(0.42)\end{array}$ & $\begin{array}{l}1.36 \\
(0.17)\end{array}$ & $\begin{array}{l}2.66 \\
(0.01)\end{array}$ & $\begin{array}{l}3.62 \\
(0.00)\end{array}$ & $\begin{array}{r}-0.27 \\
(0.79)\end{array}$ & $\begin{array}{l}1.11 \\
(0.27)\end{array}$ & $\begin{array}{l}2.32 \\
(0.02)\end{array}$ & $\begin{array}{l}3.30 \\
(0.00)\end{array}$ \\
\hline MSEMKG & $\begin{array}{l}0.68 \\
(0.49)\end{array}$ & $\begin{array}{l}0.33 \\
(0.74)\end{array}$ & $\begin{array}{l}0.48 \\
(0.63)\end{array}$ & $\begin{array}{l}1.00 \\
(0.31)\end{array}$ & $\begin{array}{l}1.57 \\
(0.12)\end{array}$ & $\begin{array}{l}1.09 \\
(0.28)\end{array}$ & $\begin{array}{l}1.42 \\
(0.15)\end{array}$ & $\begin{array}{l}1.92 \\
(0.05)\end{array}$ \\
\hline MSEMUI* & $\begin{array}{l}1.70 \\
(0.09)\end{array}$ & $\begin{array}{l}2.57 \\
(0.01)\end{array}$ & $\begin{array}{l}2.90 \\
(0.00)\end{array}$ & $\begin{array}{l}3.84 \\
(0.00)\end{array}$ & $\begin{array}{l}1.68 \\
(0.09)\end{array}$ & $\begin{array}{l}2.86 \\
(0.00)\end{array}$ & $\begin{array}{l}3.47 \\
(0.00)\end{array}$ & $\begin{array}{l}4.22 \\
(0.00)\end{array}$ \\
\hline MSEXEM & $\begin{array}{l}0.72 \\
(0.47)\end{array}$ & $\begin{array}{l}1.67 \\
(0.09)\end{array}$ & $\begin{array}{l}1.94 \\
(0.05)\end{array}$ & $\begin{array}{l}2.34 \\
(0.02)\end{array}$ & $\begin{array}{l}2.60 \\
(0.01)\end{array}$ & $\begin{array}{l}1.97 \\
(0.05)\end{array}$ & $\begin{array}{l}1.71 \\
(0.09)\end{array}$ & $\begin{array}{l}2.11 \\
(0.03)\end{array}$ \\
\hline JPMUSU & $\begin{array}{l}1.22 \\
(0.22)\end{array}$ & $\begin{array}{l}1.63 \\
(0.10)\end{array}$ & $\begin{array}{l}1.31 \\
(0.19)\end{array}$ & $\begin{array}{l}1.55 \\
(0.12)\end{array}$ & $\begin{array}{l}0.65 \\
(0.51)\end{array}$ & $\begin{array}{l}0.23 \\
(0.81)\end{array}$ & $\begin{array}{r}-0.14 \\
(0.88)\end{array}$ & $\begin{array}{l}0.58 \\
(0.56)\end{array}$ \\
\hline JPMJPU & $\begin{array}{l}3.41 \\
(0.00)\end{array}$ & $\begin{array}{l}2.89 \\
(0.00)\end{array}$ & $\begin{array}{l}1.87 \\
(0.06)\end{array}$ & $\begin{array}{l}1.26 \\
(0.20)\end{array}$ & $\begin{array}{l}5.14 \\
(0.00)\end{array}$ & $\begin{array}{l}3.93 \\
(0.00)\end{array}$ & $\begin{array}{l}2.40 \\
(0.02)\end{array}$ & $\begin{array}{l}2.07 \\
(0.04)\end{array}$ \\
\hline JAGALL & $\begin{array}{c}-0.29 \\
(0.77)\end{array}$ & $\begin{array}{l}0.40 \\
(0.69)\end{array}$ & $\begin{array}{l}1.23 \\
(0.22)\end{array}$ & $\begin{array}{l}0.60 \\
(0.54)\end{array}$ & $\begin{array}{r}-1.61 \\
(0.11)\end{array}$ & $\begin{array}{r}-0.33 \\
(0.74)\end{array}$ & $\begin{array}{l}0.79 \\
(0.43)\end{array}$ & $\begin{array}{l}0.31 \\
(0.75)\end{array}$ \\
\hline JPMUKU & $\begin{array}{l}0.98 \\
(0.33)\end{array}$ & $\begin{array}{l}1.24 \\
(0.21)\end{array}$ & $\begin{array}{l}1.70 \\
(0.09)\end{array}$ & $\begin{array}{l}1.48 \\
(0.14)\end{array}$ & $\begin{array}{l}1.49 \\
(0.14)\end{array}$ & $\begin{array}{l}1.59 \\
(0.11)\end{array}$ & $\begin{array}{l}1.63 \\
(0.10)\end{array}$ & $\begin{array}{l}1.25 \\
(0.21)\end{array}$ \\
\hline SBSZEUE & $\begin{array}{l}0.62 \\
(0.53)\end{array}$ & $\begin{array}{l}0.36 \\
(0.71)\end{array}$ & $\begin{array}{r}-0.34 \\
(0.73)\end{array}$ & $\begin{array}{r}-0.67 \\
(0.50)\end{array}$ & $\begin{array}{l}0.55 \\
(0.58)\end{array}$ & $\begin{array}{l}0.95 \\
(0.34)\end{array}$ & $\begin{array}{c}-0.09 \\
(0.93)\end{array}$ & $\begin{array}{r}-0.63 \\
0.53\end{array}$ \\
\hline JPMPTOT & $\begin{array}{l}0.75 \\
(0.45)\end{array}$ & $\begin{array}{l}1.54 \\
(0.12)\end{array}$ & $\begin{array}{l}1.31 \\
(0.19)\end{array}$ & $\begin{array}{l}1.48 \\
(0.14)\end{array}$ & $\begin{array}{l}1.77 \\
(0.08)\end{array}$ & $\begin{array}{l}2.60 \\
(0.01)\end{array}$ & $\begin{array}{l}2.36 \\
(0.02)\end{array}$ & $\begin{array}{l}2.24 \\
(0.02)\end{array}$ \\
\hline JPEC $3 \mathrm{M}^{* * *}$ & $\begin{array}{l}6.71 \\
(0.00)\end{array}$ & $\begin{array}{l}2.10 \\
(0.04)\end{array}$ & $\begin{array}{l}2.27 \\
(0.02)\end{array}$ & $\begin{array}{l}1.96 \\
(0.05)\end{array}$ & $\begin{array}{l}11.96 \\
(0.00)\end{array}$ & $\begin{array}{l}2.97 \\
(0.00)\end{array}$ & $\begin{array}{l}3.06 \\
(0.00)\end{array}$ & $\begin{array}{l}2.47 \\
(0.01)\end{array}$ \\
\hline
\end{tabular}

Note. That, only for JPEC3M (Cash) we can reject the hypothesis of IID. (***) 1\%, (**) 5\%, (*) $10 \%$

estimate of the tails of the distribution, thus reducing the power of the value-at-risk estimates (see, McNeil and Frey, 2000). This effect is less evident for portfolio applications, unless the objective function is described by the conditional VaR of the portfolio returns, as documented by Kaut et al. (2003). As seen in Appendix B:, only the asset class representing the investment in cash (JPEC3M) rejects the null hypothesis of IID. In this case, we should carry our simulation using a block bootstrap (Efron and Tibshirani, 1998) or a filtered bootstrap (Barone-Adesi et al., 2002). Note, however, that the standard deviation of JPEC3M is ten times smaller than the other series employed, so we believe that the possible biases introduced by the choice of the correct block size, or the specification of the filter models, could reduce the effectiveness of such methods with respect to the simple bootstrap procedure adopted. A deeper analysis of this aspect is outside the scope of the present paper, thus we focus only on the sampling error.

The statistic under analysis is the portfolio allocation vector $\mathbf{x}=\left[x_{1}, x_{2}, \ldots, x_{N}\right]$. The goal of the analysis is to build a confidence interval around the estimate $\mathbf{x}^{*}$ of the true value $\mathbf{x}$, for a given confidence level $\alpha$.

For this purpose, we selected $B$ independent bootstrap samples $\Omega^{* 1}, \Omega^{* 2}, \ldots, \Omega^{* B}$. Each sample consists of $S$ scenarios sampled according to the rules given in Section 4. For each bootstrapped sample, we solved model $\mathcal{M}(\cdot)$ given by the Eqs. (26)-(32). We thus obtained 
Table 4 Percentile intervals for confidence level $\alpha=5 \%$ and sample size 1000 and 2000. The model is run for target return $4 \%$, time horizon of 10 years, and risk aversion low

\begin{tabular}{lllll}
\hline & \multicolumn{4}{c}{$S=1000$} \\
\cline { 2 - 5 } & $x_{i}^{*}$ & $x_{i}^{*(\alpha)}$ & $x_{i}^{*(1-\alpha)}$ & $x_{i}^{*(1-\alpha)}-x_{i}^{*(\alpha)}$ \\
\hline JPEC3M & 0.0384 & 0.0000 & 0.2319 & 0.2319 \\
JPMPTOT & 0.0527 & 0.0389 & 0.0719 & 0.0330 \\
MSEMUI & 0.0525 & 0.0233 & 0.0931 & 0.0698 \\
MSNAMR & 0.8564 & 0.6962 & 0.8971 & 0.2009 \\
$S=$ 2000 & & & & \\
JPEC3M & 0.0271 & 0.0000 & 0.1031 & 0.1031 \\
JPMPTOT & 0.0529 & 0.0476 & 0.0653 & 0.0177 \\
MSEMUI & 0.0536 & 0.0255 & 0.0817 & 0.0562 \\
MSNAMR & 0.8664 & 0.8238 & 0.8971 & 0.0733 \\
\hline
\end{tabular}

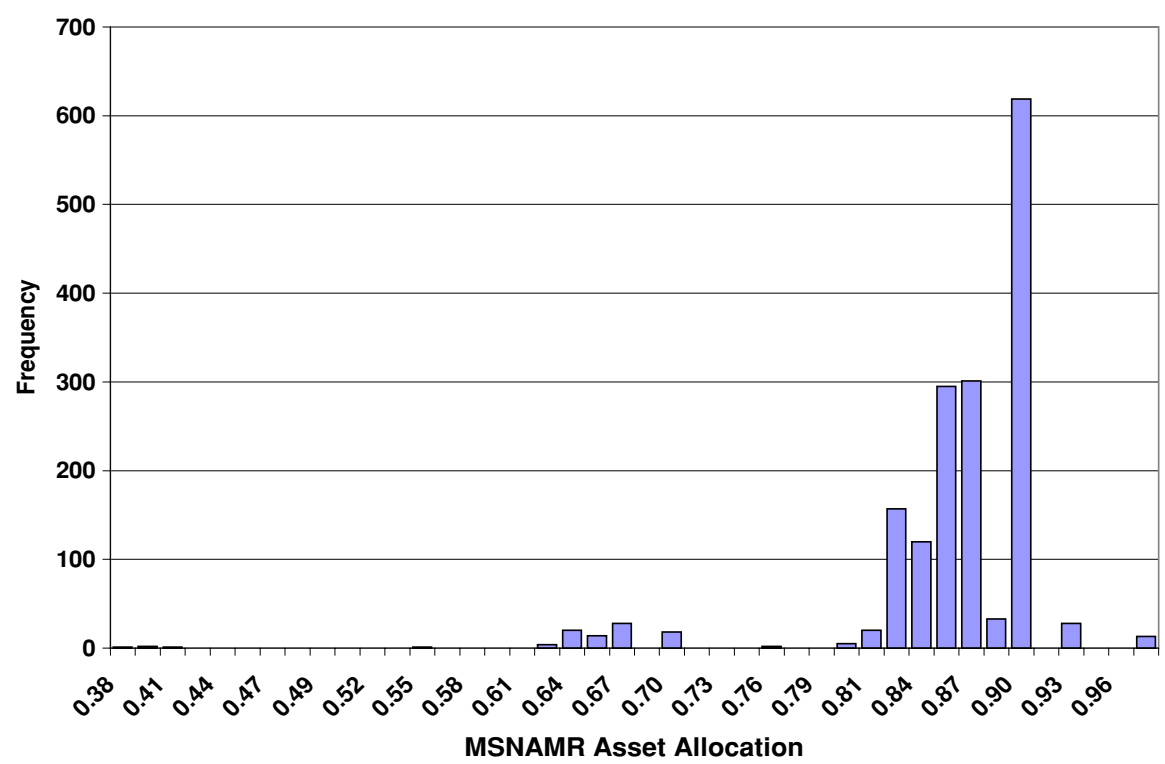

Fig. 10 Histogram of one thousands bootstrap replications of the MSNAMR asset allocation estimate

$$
\mathbf{x}^{*}(b)=\mathcal{M}\left(\Omega^{* b}\right) \quad b=1,2, \ldots, B
$$

The $i$-th component of the vector of estimates, $\mathbf{x}^{*}$, is given by

$$
x_{i}^{*}=\frac{\sum_{b=1}^{B} x_{i}^{*}(b)}{B} .
$$

In Fig. 10 we display the bootstrap sample distribution of the MSNAMR asset allocation. As it can be observed, the histogram is not symmetric and does not resemble a normal distribution. In this case we cannot use the standard confidence interval for the true value of $\mathbf{x}$. As suggested in Efron and Tibshirani, a possible alternative is to resort to confidence intervals based on percentiles of the bootstrap distribution of the statistic under exam. 


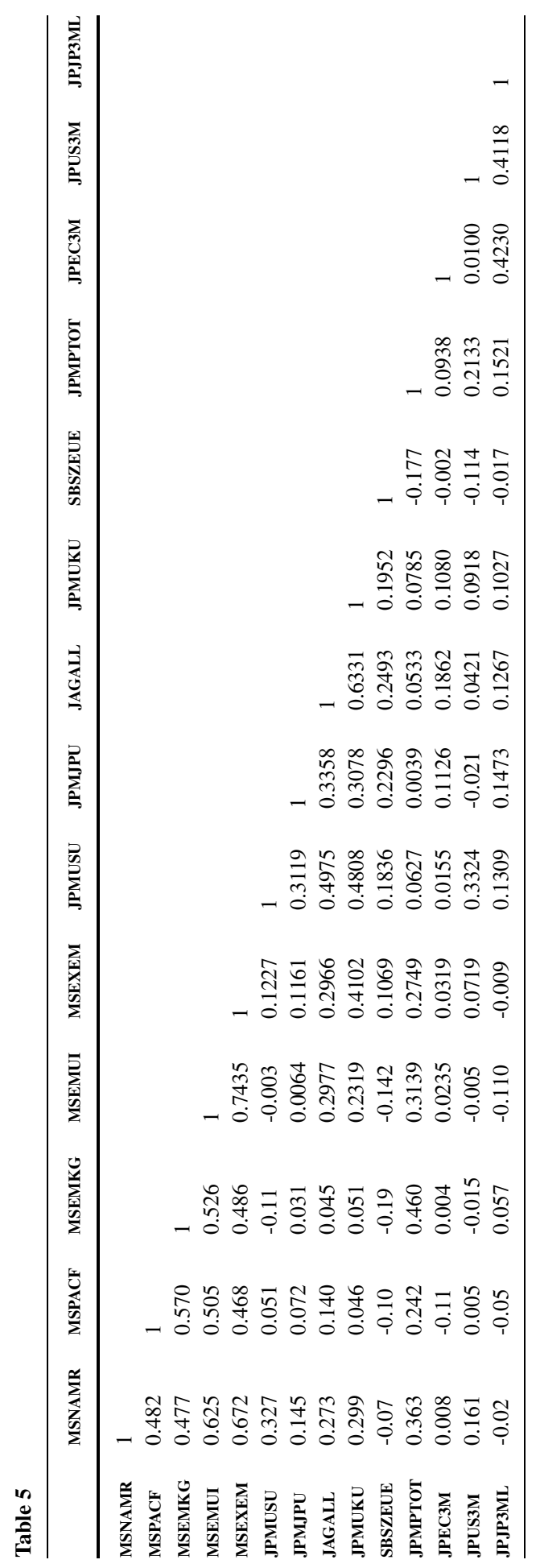


Given a set of ordered bootstrap replications of the $i$-th asset class allocation estimate, $x_{i}^{*}(b), b=1,2, \ldots, B$, we denote by $x_{i}^{*(\alpha)}$ the $B \cdot \alpha$ th empirical percentile and with $x_{i}^{*(1-\alpha)}$ the $B \cdot(1-\alpha)$ th empirical percentile.

In our experiment, we set $B=1000$ and sample size $S=1000,2000$. The confidence bands for $\alpha=90 \%$ and for asset allocations diverse from zero are reported in Table 4.

Note that, by doubling the size of the sample $S$ we were able to half the width of the confidence interval. A sample size of 5000 scenarios (not reported here) allows more stable estimates of the portfolio asset allocations.

\section{References}

Barberis, N., M. Huang, and T. Santos. (2001, February). "Prospect Theory and Asset Prices." Quarterly Journal of Economics, 116(1), 1-53.

Barone-Adesi, G., K. Giannopoulos, and L. Vosper. (2002). "Backtesting Derivative Portfolios with Filtered Historical Simulation." European Financial Management, 8, 31-58.

Basak, S. (2002). "A Comparative Study of Portfolio Insurance." Journal of Economic Dynamics and Control, 26, 1217-1241.

Basak, S. and A. Shapiro. (2001, Summer). "Value-at-Risk based Risk Management: Optimal Policies and Asset Prices." The Review of Financial Studies, 14(2), 371-405.

Benartzi, S. and R. Thaler. (1995). "Myopic Loss Aversion and the Equity Premium Puzzle." Quarterly Journal of Economics, 110(1), 73-92.

Berger, A. and J. Mulvey. (1998). "The HOME Account Advisor: Asset and Liability Management for Individual Investors." In W. Ziemba and J. Mulvey (eds.), Worldwide Asset and Liability Modeling, pp. 634-665. Cambridge, UK: Cambridge University Press.

Brock, W., W. Dechert, and J. Scheinkman. (1996). "A Test for Independence Based on the Correlation Dimension. Econometrics Reviews, 15, 197-235.

Brooke, A., D. Kendrick, and A. Meeraus. (1992). GAMS: A User's Guide, Release 2.25. Danvers, MA 01923: The Scientific Press, Boyd and Fraser Publishing Company.

Campbell, J. and L. Viceira. (2002). Strategic Asset Allocation-Portfolio Choice for Long-Term Investors. Claredon Lectures in Economics. New York: Oxford University Press.

Cario, D., D. Myers, and W. Ziemba. (1998). "Concepts, Technical Issues, and Uses of the Russel-Yasuda Kasai Financial Planning Model.” Operations Research, 46(4), 450-462.

Consiglio, A., F. Cocco, and S. Zenios. (2001). "The Value of Integrative Risk Management for Insurance Products with Minimum Guarantees.” Journal of Risk Finance, 2(3), 1-11.

Consiglio, A., F. Cocco, and S. Zenios. (2004, July-August). "www.personal_asset_allocation." Interfaces, 34(4), 287-302.

Consiglio, A., D. Saunders, and S. Zenios. (2003). "Insurance League: Italy vs. UK." Journal of Risk Finance, $4(4), 47-54$

Dembo, R. and H. Mausser. (2000, June). "The Put-Call Efficient Frontier." Algo Research Quarterly, 3(1), $13-25$.

Dembo, R. and D. Rosen. (1999). "The Practice of Portfolio Replication. A Practical Overview of Forward and Inverse Problems." Annals of Operations Research, 85, 267-284.

Efron, B. and R. Tibshirani. (1998). An Introduction to the Bootstrap. London: Chapman and Hall.

Flavin, M. and T. Yamashita. (2002). "Owner-Occupied Housing and the Composition of the Household Portfolio." The American Economic Review, 92(1), 345-362.

Guiso, L., M. Haliassos, and T. Japelli (Eds.). (2001). Household Portfolios. Cambridge, MA: The MIT Press.

Harker, P. and S. Zenios (Eds.). (2000). Performance of Financial Institutions: Efficiency, Innovation, Regulations. Cambridge, England: Cambridge University Press.

Jorion, P. (2001, August). Value at Risk: The New Benchmark for Controlling Market Risk, 2nd ed. McGrawHill.

Kahneman, K. and A. Tversky. (1979). "Prospect Theory: An Analysis of Decision Under Risk.” Econometrica 47(2), 263-291.

Kaut, M., S. Wallace, H. Vladimirou, and S.A. Zenios. (2003). "Stability Analysis of a Portfolio Management Model Based on the Conditional Value-at-Risk Measure." Working paper, HERMES European Center of Excellence on Computational Finance and Economics.

Kritzman, M. and D. Rich. (2002, May/June). "The Mismeasurement of Risk.” Financial Analysts Journal, 58(3), 91-99. 
Liu, J., F. Longstaff, and J. Pan (2003). "Dynamic Asset Allocation with Event Risk." Journal of Finance, 58(1), 231-259.

Markowitz, H. (1991). "Individual Versus Institutional Investing." Financial Services Review, 1(1), 1-8.

McNeil, A. and R. Frey. (2000). "Estimation of Tail-Related Risk Measures for Heteroscedastic Financial Time Series: An Extreme Value Approach." Journal of Empirical Finance, 7(3), 225-416.

Mehra, R. and E. Prescott. (1985). "The Equity Premium: A Puzzle." Journal of Monetary Economics, 15, $145-162$.

Milevsky, M., K. Ho, and C. Robinson. (1997). "Asset Allocation via the Conditional First Exit Time or How to Avoid Outliving Your Money." Review of Quantitative Finance and Accounting, 9(1), 53-70.

Mulvey, J. and A. Thorlacius. (1998). "The Towers Perrin Global Capital Market Scenario Generation System." In W. Ziemba and J. Mulvey (Eds.), Worldwide Asset and Liability Modeling, pp. 286-312. Cambridge, UK: Cambridge University Press.

Palmquist, J., S. Uryasev, and P. Krokhmal. (2001/02, Winter). "Portfolio Optimization with Conditional Value-at-Risk Criterion." Journal of Risk, 4(2), 11-27.

Rudolf, M. and W. Ziemba. (2004). "Intertemporal Surplus Management." Journal of Economic Dynamics and Control, 28(5), 975-990.

Uryasev, S. and R. Rockafellar. (2000). "Optimization of Conditional Value-at-Risk.” Journal of Risk, 2(3), $21-41$.

Ziemba, W. and J. Mulvey (Eds.). (1998). Worldwide Asset and Liability Modeling. Cambridge, MA: Cambridge University Press. 